\title{
La percepción del agua en el cuento "Es que somos muy pobres" de Juan Rulfo
}

\author{
The Perception of Water in the Story "It Is that We Are Very Poor" by Juan \\ Rulfo
}

\section{A percepção da água na história "Somos muito pobres" de Juan Rulfo}

Carmina Alejandra García Serrano

Universidad de Guadalajara, Centro Universitario de Ciencias Sociales y Humanidades.

Departamento de Letras, México

carminaburana74@hotmail.com

https://orcid.org/0000-0003-0333-7381

\section{Resumen}

Generalmente, en nuestra cultura, el agua aparece asociada a cualidades positivas como la vida, la pureza, lo inodoro y lo insaboro, pero en el cuento "Es que somos muy pobres" de Juan Rulfo, publicado en 1953, el agua se percibe con cualidades negativas. En el presente artículo se utiliza un método de tipo cualitativo semántico para analizar el cuento, mediante el cual se describen las formas de nominar el agua, los calificativos del agua, el agua y los sentidos, las acciones del agua y la correlación entre determinismo natural y determinismo social. Se intenta dejar en claro, mediante los distintos abordajes que permite el análisis cualitativo semántico, que el agua y sus distintas manifestaciones son negativas, productoras de situaciones que se relacionan con el determinismo social planteado en el cuento. De igual forma, se intenta hacer evidente, a partir de la percepción que se tiene sobre el agua, cómo esta influye en la percepción de las cualidades morales de los personajes femeninos del cuento, específicamente las hermanas del narrador.

Palabras clave: agua, concepto, cualidad, determinismo, percepción. 


\section{Revista Iberoamericana \\ de las Ciencias Sociales y Humanísticas}

ISSN: $2395-7972$

\section{Abstract}

Generally, in our culture, water appears associated with positive qualities such as life, purity, odorless, and tasteless, but in Juan Rulfo's story “It Is that We Are Very Poor", published in 1953, water is perceived with negative qualities. In this article a semantic qualitative method is used to analyze the story, which is described by the ways of naming water, the qualifiers of water, water and the senses, the actions of water and the correlation between natural determinism and social determinism. An attempt is made to make it clear, through the different approaches that allow qualitative semantic analysis, that water and its different manifestations are negative, producing situations that are related to the social determinism raised in the story. In the same way, an attempt is made to make evident, from the perception that one has about the water, how it influences the perception of the moral qualities of the female characters in the story, specifically the narrator's sisters.

Keywords: water, concept, quality, determinism, perception.

\section{Resumo}

Geralmente, em nossa cultura, a água aparece associada a qualidades positivas como vida, pureza, inodoro e insípido, mas na história de Juan Rulfo "Es que somos muy poor", publicada em 1953, a água é percebida com qualidades negativas. Neste artigo, é utilizado um método semântico qualitativo para analisar a história, através do qual são descritas as formas de nomear a água, os qualificadores da água, a água e os sentidos, as ações da água e a correlação entre o determinismo natural e o determinismo social. Procura-se deixar claro, por meio das diferentes abordagens que a análise semântica qualitativa permite, que a água e suas diferentes manifestações são negativas, produzindo situações que se relacionam com o determinismo social levantado na história. Da mesma forma, procura-se evidenciar, a partir da percepção que se tem da água, como ela influencia a percepção das qualidades morais das personagens femininas da história, especificamente das irmãs da narradora.

Palavras-chave: água, conceito, qualidade, determinismo, percepção.

Fecha Recepción: Febrero 2020

Fecha Aceptación: Diciembre 2020 


\section{Introducción}

En el cuento "Es que somos muy pobres" hay una percepción negativa y determinista de la naturaleza, específicamente del agua, la cual se asocia a un determinismo social vinculando la pobreza y la no posesión de bienes materiales a la perdición, y a no poder encontrar un marido. Aquí se plantea un vínculo entre la naturaleza y las malas costumbres y la perdición de las hermanas del narrador. También se explica cómo el foco principal del cuento es el agua, la cual se percibe como fuente de desgracias. Tiene una función negativa, pues acarrea ruina, muerte de la vaca y su becerro, invasión de casas y del pueblo, destrucción de casas y cosechas, y se lleva árboles. Al mismo tiempo, es objeto de calificativos no implicados por el concepto cultural del agua y se asocia a los cinco sentidos básicos de percepción del ser humano.

\section{Marco teórico-metodológico}

El análisis que se realiza en esta investigación busca explicitar los mecanismos por medio de los cuales el narrador del cuento "Es que somos muy pobres" de Juan Rulfo percibe el agua, por lo que se hace necesario dejar en claro qué es la percepción y cuáles son sus componentes. Lupón, Torrents y Quevedo (2012) definen percepción como:

El proceso de extracción activa de información de los estímulos, y elaboración y organización de representaciones para la dotación de significado. A diferencia del resto de las funciones cognitivas, presenta la característica distintiva de tener su origen en la interacción física que se da entre el medio y el organismo a través de los sentidos (vista, oído, olfato, gusto y tacto) con lo que viene a ser el punto de encuentro entre lo físico y lo mental (p. 4).

En el análisis se presenta cómo la percepción del agua se realiza por los cinco sentidos (vista, oído, olfato, gusto y tacto). Esta percepción proviene del contacto del narrador con su medio. Pero lo que se cataloga como percepción no depende únicamente de la información que perciben los sentidos, sino que estos estímulos sensoriales se relacionan en el cerebro con el conocimiento previo del perceptor, su ideología y su cultura. Rivera, Arellano y Molero (2000) señalan que los componentes de la percepción son los siguientes:

Aunque los estímulos sensoriales pueden ser los mismos, para todas las personas, cada una de ella percibirá cosas distintas. Este fenómeno nos lleva a concebir la percepción como resultado de dos tipos de inputs: 


\section{Revista Iberoamericana de las Ciencias Sociales y Humanísticas}

1) Las sensaciones o el estímulo físico que proviene del medio externo, en forma de imágenes, sonidos, aromas, etc.

2) Los inputs internos que provienen del individuo, como son las necesidades, motivaciones y experiencia previa, y que proporcionarán una elaboración psicológica distinta de cada uno de los estímulos externos (p. 17).

Los objetos de la realidad tienen varios atributos o características. En el campo de lo visual, por ejemplo, Smith y Kosslyn (2008) señalan lo siguiente:

Las características visuales incluyen puntos y bordes, colores y formas, movimientos y texturas. Todos estos son atributos que en sí mismos no son objetos, pero que en combinación pueden definir los objetos que vemos. Son los elementos con los que se construye la percepción (p. 60).

Que la percepción tenga dos componentes toma importancia por el hecho de que el narrador emite juicios sobre lo que percibe, clasifica el agua al nominarla, capta de ella ciertos atributos que selecciona y organiza al punto de presentar una visión negativa del agua moldeada por su experiencia y conocimiento cultural e ideológico. Vargas (1994) dice al respecto de la naturaleza biológica y cultural-ideológica de la percepción:

La percepción es biocultural porque, por un lado, depende de los estímulos físicos y sensaciones involucrados $\mathrm{y}$, por otro lado, de la selección y organización de dichos estímulos y sensaciones. Las experiencias sensoriales se interpretan y adquieren significado moldeadas por pautas culturales e ideológicas (p. 47).

Para entender cómo se construye la percepción del agua del narrador, se hace indispensable un análisis que identifique la forma en que se percibe el agua y sus diferentes nominaciones, así como sus atributos de percepción, su relación con los sentidos y la forma en que se relacionan con el contexto, conocimiento previo y experiencias del narrador, quien, como se ha adelantado, terminará relacionando el agua del río con la perdición de sus hermanas en el ámbito social, precisamente porque está relacionando lo que percibe con su ideología y su experiencia previa.

En el aspecto metodológico, se realiza un análisis semiótico que se apoya en las propuestas de Fontanille (2016a, 2016b) sobre cómo un objeto toma dimensiones actanciales y la semiótica de los olores aplicada al olor del agua del río, y de Zilberberg (2016) para el estudio de las valencias intensivas y extensivas en el fluir del agua. El análisis semiótico es 
Revista Iberoamericana

de las Ciencias Sociales y

Humanísticas

ISSN: $2395-7972$

la base para explicar las diferentes nominaciones del agua y sus variantes de manifestación, los atributos del agua y las características que tiene el agua en su relación con los cinco sentidos.

\section{Las formas de nominar el agua según se percibe}

Existen variadas formas en que el agua se presenta en el texto y dependiendo de la manera en que se manifiesta recibe un nombre específico. En el texto, estas variantes de nominación son importantes pues son determinadas por diferentes manifestaciones del agua: el lugar de donde procede, por dónde se mueve, por la forma que toma, por su intensidad, su cantidad, el tiempo en que se manifiesta y sus características de identidad, como se pude ver en la tabla 1.

Tabla 1. Nominaciones del agua según sus manifestaciones

\begin{tabular}{|l|l|}
\hline Nominación del agua & $\begin{array}{l}\text { Variantes de manifestación en el texto: plano, intensidad } \\
\text { y forma }\end{array}$ \\
\hline Lluvia & $\begin{array}{l}\text { Procede del plano celeste. } \\
\text { Forma: manifestación del agua en gotas. } \\
\text { Antensidad: moderada. }\end{array}$ \\
\hline Olas de agua & $\begin{array}{l}\text { Procede del plano celeste con fuerte intensidad. } \\
\text { Manifestación del agua en gotas o goterones. }\end{array}$ \\
& $\begin{array}{l}\text { Proceden del plano celeste en el texto, con tanta intensidad } \\
\text { que ya no son gotas sino olas, las cuales, como se verá más } \\
\text { adelante, presentan características orientacionales. }\end{array}$ \\
\hline Agua & $\begin{array}{l}\text { Forma: la ola es una onda que se forma en el agua, tiene } \\
\text { altura y amplitud. }\end{array}$ \\
\hline $\begin{array}{l}\text { Cae del cielo o forma parte del río. } \\
\text { Se mueve en plano celeste y terrestre. }\end{array}$ \\
\hline
\end{tabular}




\begin{tabular}{|c|c|}
\hline & $\begin{array}{l}\text { El texto se refiere a ella generalmente con fuerte intensidad. } \\
\text { Se presenta en diversas formas. }\end{array}$ \\
\hline Río & $\begin{array}{l}\text { Curso del agua que se manifiesta en el plano terrestre con } \\
\text { características orientacionales. En el texto comienza a } \\
\text { expandir sus límites. El agua que contiene presenta } \\
\text { intensidad de volumen y de fuerza de movimiento } \\
\text { (corriente). }\end{array}$ \\
\hline Nublazones & $\begin{array}{l}\text { Agua condensada en el cielo que aún no cae y que es síntoma } \\
\text { de lluvia. Se maneja en el plano celeste. La forma del } \\
\text { sustantivo refiere gran tamaño. }\end{array}$ \\
\hline Chorros & $\begin{array}{l}\text { Forma de salir del agua, manifiesta fuerte intensidad y } \\
\text { cantidad. Se manifiesta en el plano terrestre. }\end{array}$ \\
\hline Pedazo de río & $\begin{array}{l}\text { Forma en que se describe una nueva parte del río, la cual era } \\
\text { una casa. Se manifiesta en el plano terrestre. }\end{array}$ \\
\hline Corriente & $\begin{array}{l}\text { Manifestación del río que invade terreno de casa. Tiene } \\
\text { fuerte intensidad. Se manifiesta en el plano terrestre. }\end{array}$ \\
\hline Creciente & $\begin{array}{l}\text { Elevación del nivel del curso de agua, manifiesta intensidad. } \\
\text { Se presenta en el plano terrestre como parte del río. }\end{array}$ \\
\hline Amontonadero de agua & $\begin{array}{l}\text { Acumulación de agua como si fuera una cosa o un conjunto } \\
\text { de cosas. Se manifiesta en el plano terrestre. }\end{array}$ \\
\hline La cosa aquella (río) & $\begin{array}{l}\text { Forma de denominar a un río que parece haber perdido sus } \\
\text { características de identidad. Se manifiesta en el plano } \\
\text { terrestre. Tiene fuerte intensidad. }\end{array}$ \\
\hline El río este & $\begin{array}{l}\text { Forma de denominar al río en el presente. El río se } \\
\text { desidentifica con respecto al que solía ser. Se manifiesta en } \\
\text { el plano terrestre. Tiene fuerte intensidad. }\end{array}$ \\
\hline El mismo río & $\begin{array}{l}\text { Forma de denominar al río antes del aguacero y de que } \\
\text { creciera. Se trata del río de la vida cotidiana. Su intensidad } \\
\text { era moderada. Se manifiesta en el plano terrestre. }\end{array}$ \\
\hline
\end{tabular}




\section{Revista Iberoamericana de las Ciencias Sociales y Humanísticas}

\begin{tabular}{|l|l|}
\hline Llanto & $\begin{array}{l}\text { El agua en forma de lágrimas. Es de fuerte intensidad, por el } \\
\text { movimiento del pecho de quien llora. Se manifiesta en el } \\
\text { plano humano. }\end{array}$ \\
\hline $\begin{array}{l}\text { Chorretes de agua sucia } \\
\text { (lágrimas) }\end{array}$ & $\begin{array}{l}\text { Forma de denominar al agua producto del llanto que corre } \\
\text { por la cara de Tacha. Fuerte intensidad por la alusión a } \\
\text { "chorro". Se manifiesta en el plano humano. }\end{array}$ \\
\hline
\end{tabular}

Fuente: Elaboración propia

Fernández C. A. (2012) presenta al agua en la naturaleza de la siguiente forma: El agua cubre más del $70 \%$ de la superficie del planeta; se la encuentra en océanos, lagos, ríos; en el aire, en el suelo. Es la fuente y el sustento de la vida, contribuye a regular el clima del mundo y con su fuerza formidable modela la Tierra. Posee propiedades únicas que la hacen esencial para la vida (p. 148).

En el texto también el agua se encuentra en diferentes partes como ríos, aire, suelo, que son las que se mencionan. Fernández C. A. (2012) también habla de su fuerza modeladora, que es la que se hace presente en el texto por medio de la intensidad de la lluvia, la cual hace crecer el río y este a su vez comienza a transgredir sus límites e invadir los del pueblo. El río comienza a crecer y modifica el paisaje. Ahora las casas, como la de la Tambora, son un pedazo de río. En la anterior cita también se presenta el agua como esencial para la vida. En el cuento, el agua del río es esencia de muerte y destrucción. Cabe aclarar que, en el cuento, el agua no posee las cualidades que culturalmente se le adjudican, sino que maneja unas antitéticas a estas.

Chevalier y Gheerbrant (1995) afirman que "las significaciones simbólicas del agua pueden reducirse a tres temas dominantes: fuente de vida, medio de purificación y centro de regeneración” (p. 52). Indudablemente, después de la inundación el pueblo tendrá que regenerarse parcialmente o reconstruir las partes afectadas. Sin embargo, Chevalier y Gheerbrant (1995) también indican que "el agua es fuente de vida y fuente de muerte, creadora y destructora" (p. 54) y que "puede actuar como la muerte. Las grandes aguas anuncian en la Biblia las pruebas. El desencadenamiento de las aguas es el símbolo de las grandes calamidades" (p. 56). Como se puede observar, las principales significaciones culturales del agua son positivas y asociadas a la vida, aunque también posee significaciones 


\section{Revista Iberoamericana \\ de las Ciencias Sociales y Humanísticas}

religiosas asociadas a la destrucción. En este cuento, el río y el agua están vinculados a la destrucción, pero no en un sentido religioso, sino natural, social y moral.

Por otra parte, el río se nomina por medio de sustantivos y de sintagmas nominales. El texto es rico en formas de nominar el agua según se manifiesta (como se vio en la tabla 1) y se percibe en un momento determinado, con características orientacionales, determinadas por su movimiento. La orientación vertical determina los puntos: arriba-abajo. La orientación horizontal se precisa por la forma en que el agua se mueve en el plano terrestre, con determinada intensidad y una forma específica de manifestación (como también se observó en la tabla 1). A continuación, en la tabla 2, se explica la estructura de la forma de nominar el agua y el tipo de orientación en que se manifiesta.

Tabla 2. Estructura de la forma de nominar y coordenadas orientacionales del agua

\begin{tabular}{|c|c|}
\hline Nominación del agua & $\begin{array}{l}\text { Estructura de la forma de nominar y coordenadas } \\
\text { orientacionales del agua }\end{array}$ \\
\hline Lluvia & $\begin{array}{l}\text { Sustantivo común concreto. } \\
\text { Agua en movimiento con orientación vertical. }\end{array}$ \\
\hline Aguacero & $\begin{array}{l}\text { Sustantivo derivado del sustantivo agua. El sufijo derivativo } \\
\text {-ero denota intensidad y gran cantidad. } \\
\text { Agua en movimiento con orientación vertical. }\end{array}$ \\
\hline Olas de agua & $\begin{array}{l}\text { Sintagma nominal. La palabra agua tiene la función de } \\
\text { especificar la naturaleza o esencia del sustantivo ola. } \\
\text { La ola tiene dos tipos de orientación: vertical, porque la ola } \\
\text { tiene una altura, y horizontal, por su amplitud y movimiento. }\end{array}$ \\
\hline Agua & $\begin{array}{l}\text { Sustantivo común concreto. } \\
\text { Se utiliza para nombrar el agua con orientación vertical (la } \\
\text { de la lluvia). Y también se utiliza para denominar el agua del } \\
\text { río. }\end{array}$ \\
\hline Río & Sustantivo común concreto. \\
\hline
\end{tabular}




\begin{tabular}{|c|c|}
\hline & $\begin{array}{l}\text { Se utiliza para nominar el agua con orientación horizontal } \\
\text { que corre por un cauce. En el texto se alimenta del agua que } \\
\text { cae del cielo. }\end{array}$ \\
\hline Nublazones & $\begin{array}{l}\text { Sustantivo común concreto. El sufijo -on refiere gran } \\
\text { magnitud o intensidad. } \\
\text { Agua que se encuentra en la orientación vertical arriba. Se } \\
\text { encuentra condensada, carece de movimiento. }\end{array}$ \\
\hline Chorros & $\begin{array}{l}\text { Sustantivo común concreto. } \\
\text { Agua en movimiento con orientación horizontal en el texto } \\
\text { que sale de la casa. }\end{array}$ \\
\hline Pedazo de río & $\begin{array}{l}\text { Sintagma nominal. El sustantivo río especifica al sustantivo } \\
\text { pedazo. } \\
\text { Es un proceso de fragmentación para llamar a una nueva } \\
\text { parte del río, la cual antes era una casa. }\end{array}$ \\
\hline Corriente & $\begin{array}{l}\text { Sustantivo común concreto. } \\
\text { Forma de llamar al todo (río) por la parte (corriente). } \\
\text { La orientación en horizontal, pues el agua se mueve de } \\
\text { forma horizontal con fuerte intensidad. Orientación vertical, } \\
\text { se eleva en el plano terrestre de abajo hacia arriba. }\end{array}$ \\
\hline Creciente & $\begin{array}{l}\text { Sustantivo común concreto. } \\
\text { Tiene orientación vertical (arriba), pues refiere a un aumento } \\
\text { de la elevación del agua del río. }\end{array}$ \\
\hline Amontonadero de agua & $\begin{array}{l}\text { Sintagma nominal. El sustantivo agua especifica al } \\
\text { sustantivo amontonadero. El sufijo -ero refiere a gran } \\
\text { cantidad. }\end{array}$ \\
\hline
\end{tabular}




\begin{tabular}{|c|c|}
\hline & $\begin{array}{l}\text { Se manifiesta en las orientaciones horizontal y vertical pues } \\
\text { implica una altura y una anchura. }\end{array}$ \\
\hline La cosa aquella (río) & $\begin{array}{l}\text { Sintagma nominal, donde el sustantivo cosa es especificado } \\
\text { por el adjetivo demostrativo aquella. El sustantivo es } \\
\text { generalizante y el adjetivo refiere una distancia lejana entre } \\
\text { el que emite la voz (narrador) y el río (cosa). La expresión } \\
\text { se utiliza para señalar que aquello a lo que se refiere no se } \\
\text { reconoce. } \\
\text { Al referirse al río tiene como orientación la horizontalidad } \\
\text { porque el río se maneja en ese plano y verticalidad por la } \\
\text { creciente del este. }\end{array}$ \\
\hline El río este & $\begin{array}{l}\text { Sintagma nominal en el que un adjetivo demostrativo, este, } \\
\text { marca una distancia cercana entre el que emite la voz (el } \\
\text { narrador) y el río. La orientación es horizontal por el cauce } \\
\text { del río y vertical por la creciente. }\end{array}$ \\
\hline El mismo río & $\begin{array}{l}\text { Sintagma nominal en el que el adjetivo mismo especifica al } \\
\text { sustantivo río, hace referencia a una identificación de las } \\
\text { instanciaciones del río en el tiempo pasado. La orientación } \\
\text { es horizontal. }\end{array}$ \\
\hline Llanto & $\begin{array}{l}\text { Sustantivo común concreto. Tiene una orientación y } \\
\text { dirección vertical de arriba hacia abajo. }\end{array}$ \\
\hline $\begin{array}{l}\text { Chorretes de agua sucia } \\
\text { (lágrimas) }\end{array}$ & $\begin{array}{l}\text { Sintagma nominal para referirse a las lágrimas de Tacha. } \\
\text { Agua sucia especifica a chorretes. Tienen una orientación y } \\
\text { dirección vertical de arriba hacia abajo. }\end{array}$ \\
\hline
\end{tabular}

Fuente: Elaboración propia

Como se pudo apreciar en la tabla 2, las estructuras de nominación son dos: sustantivos y sintagmas nominales. Las formas de especificar son fundamentales para comprender la percepción del agua presente en el texto. El río se percibe como diferente al que ya se conocía. El narrador marca distancia cercana y lejana con respecto a él, la última es una distancia más de tipo emocional que física. Además de las especificaciones del agua 
ya vistas, a continuación se exponen otras, las cuales refuerzan la propuesta de percepción negativa del agua en el texto.

\section{Los atributos de percepción del agua}

En el cuento, el agua adquiere atributos que se alejan del concepto cultural del agua. El agua suele ser conceptuada, ya si no como incolora, sí translúcida (se puede mirar lo que hay debajo de ella). El cuento habla de un fuerte aguacero y de la inundación del pueblo generada por el río. El agua común del río, que se encontraba en la vida cotidiana del narrador, ha cambiado y su percepción la presenta con las siguientes cualidades asociadas a ciertas acciones:

Tabla 3. Calificativos y acciones del agua

\begin{tabular}{|l|l|}
\hline Atributos del agua & Acciones del agua \\
\hline Dura como tierra corrediza & Entreveró y acalambró a la vaca. \\
\hline Espesa & Se hace (proceso permanente). \\
\hline Oscura & Se hace (proceso permanente). \\
\hline Pesada & Golpeaba las costillas. \\
\hline Negra & Entreveró y acalambró a la vaca. \\
\hline Revuelta & Emite un olor. \\
\hline Sucia & Correr. \\
\hline Fría & Caía del cielo y quemaba la cebada. En \\
& el texto el agua fría quema. \\
\hline
\end{tabular}

Fuente: Elaboración propia

Estos calificativos del agua que aparecen en la tabla 3 devienen de que ha perdido las cualidades que comúnmente se observan en ella, debido al proceso de arrastre de tierra y árboles, entre otras cosas. Dos de estas acciones son violentas: golpear las costillas y entreverar y acalambrar a la vaca. Se encuentra en un proceso permanente de hacerse cada vez más pesada y oscura, al punto de que el narrador la percibe como dura y la compara con la tierra corrediza. No es tan líquida como antes. 


\section{El río antes y después del aguacero}

A partir de las nominaciones y calificativos del agua (tablas 2 y 3 ) se hace patente que el río es uno antes del aguacero y otro después de este. El río de antes posee las valencias intensivas y extensivas del fluir natural del agua dulce como las propone Zilberberg (2016).

Tabla 4. Tabla de valencias del fluir natural del agua dulce

\begin{tabular}{|l|l|l|}
\hline \multirow{2}{*}{ Valencias } & Tempo & Lentitud \\
\cline { 2 - 3 } & Tonicidad & Moderación \\
\hline Valencias & Temporalidad & Longevidad \\
\cline { 2 - 3 } Extensivas & Espacialidad & Abertura \\
\hline
\end{tabular}

Fuente: Zilberberg (2016, p. 131)

Las valencias de la tabla 4 serían correspondientes al río antes de que aumentara su creciente y sufriera una total transformación. Es el río que solía cruzar la vaca Serpentina. Presenta categorías permanentes a lo largo del tiempo a la forma de fluir del río. Pero de formar parte de los accidentes geográficos del espacio en el que tiene lugar la historia del cuento, el río cambia y se convierte en una amenaza. El prolongado aguacero (las olas de agua que cayeron del cielo) aumenta la creciente del río, el cual se desborda e invade el pueblo (calles y casas) y arrastra animales y árboles. Como se explicará más adelante, el río se transforma en un actor y sus nuevas características modifican las valencias señaladas anteriormente (ver tabla 5).

Tabla 5. Tabla de valencias del fluir del río crecido

\begin{tabular}{|l|l|l|}
\hline \multirow{2}{*}{ Valencias } & Tempo & Rapidez \\
\cline { 2 - 3 } & Tonicidad & Fuerza \\
\hline \multirow{2}{*}{ Valencias } & Temporalidad & Transitoriedad \\
\cline { 2 - 3 } & Espacialidad & Abertura \\
\hline
\end{tabular}

Fuente: Elaboración propia

Casi todas las valencias han cambiado. El río fluye con rapidez y fuerza por el gran volumen de agua que lleva, pero se trata de un fenómeno transitorio (tiene un inicio y un fin), depende de la intensidad del agua que cae del cielo, que no será eternamente un aguacero. En lo espacial, el río se expande con libertad (abertura), e invade el pueblo (entra a las casas y sube por calles). 


\section{El agua y los sentidos}

Aunque tradicionalmente se maneja que el agua es insabora e incolora, en el cuento aparece ligada a los cinco sentidos que posee el ser humano: vista, gusto, olfato, oído y tacto. No es común encontrar textos o expresiones donde se hable del olor y sabor del agua natural. Rodríguez y Silva (2003) afirman que el agua en su estado natural puede tener algún sabor u olor, aunque "aún así, persiste la idea simplista de que el agua debe ser incolora, inodora e insabora como parámetros de calidad.” (p. 166). Esta idea simplista a la que hacen referencia los autores es la noción cultural de agua. No es una idea simplista, como se pudiera percibir desde una perspectiva hidrológica, sino que se trata de la concepción compartida por los sujetos sociales que forman parte de una misma cultura. Juan Rulfo intencionalmente maneja cualidades opuestas a las que tiene el agua en una concepción compartida socialmente, excepto la de ser fría. Difieren notablemente del parámetro de calidad impuesto en la percepción social. Es por esto por lo que en el cuento el agua sí puede ser percibida por todos los sentidos, como se muestra en la tabla 6.

Tabla 6. El agua y su relación con los cinco sentidos del cuerpo

\begin{tabular}{|c|c|c|}
\hline Sentido & Expresión & Características \\
\hline Auditivo & $\begin{array}{l}\text { "El estruendo que traía el río". } \\
\text { "El sonido del río". }\end{array}$ & El río es portador del sonido. \\
\hline Auditivo & $\begin{array}{l}\text { "Ese sonido se fue haciendo igual } \\
\text { hasta traerme otra vez el sueño". }\end{array}$ & El sonido del río arrulla. \\
\hline Auditivo & $\begin{array}{l}\text { "El ruido del río era más fuerte y se } \\
\text { oía más cerca". }\end{array}$ & $\begin{array}{l}\text { El sonido se percibe ya como } \\
\text { ruido, el río ha crecido y ello se } \\
\text { determina por la cercanía del } \\
\text { sonido. }\end{array}$ \\
\hline Auditivo & $\begin{array}{l}\text { "Abajo, junto al río, hay un gran } \\
\text { ruidazal y solo se ven las bocas de } \\
\text { muchos que se abren y se cierran y } \\
\text { como que quieren decir algo; pero } \\
\text { no se oye nada". }\end{array}$ & $\begin{array}{l}\text { El ruido del río ha aumentado de } \\
\text { intensidad y se denomina como } \\
\text { ruidazal. No permite oír lo que } \\
\text { dicen otras personas. }\end{array}$ \\
\hline
\end{tabular}


Revista Iberoamericana

de las Ciencias Sociales y

Humanísticas

ISSN: 2395 - 7972

\begin{tabular}{|c|c|c|}
\hline Auditivo & $\begin{array}{l}\text { "El chapaleo del agua se oía entrar } \\
\text { por el corral". }\end{array}$ & $\begin{array}{l}\text { El agua del río suena al chocar } \\
\text { con cosas. }\end{array}$ \\
\hline Gusto & $\begin{array}{l}\text { "La creciente sigue subiendo. El } \\
\text { sabor a podrido que viene de allá". }\end{array}$ & $\begin{array}{l}\text { El agua del río sabe a podrido. } \\
\text { Esto indica estado de } \\
\text { descomposición. }\end{array}$ \\
\hline Olfato & $\begin{array}{l}\text { "Se olía como se huele una } \\
\text { quemazón". }\end{array}$ & $\begin{array}{l}\text { Se trata de una comparación del } \\
\text { olor del río con el humo. }\end{array}$ \\
\hline Olfato & $\begin{array}{l}\text { "El olor a podrido del agua } \\
\text { revuelta". }\end{array}$ & $\begin{array}{l}\text { El agua huele a podrido. Se trata } \\
\text { de agua revuelta. Hace alusión a } \\
\text { un estado de descomposición (tal } \\
\text { vez de todo lo vivo que ha } \\
\text { arrastrado el río: vegetales y } \\
\text { animales). }\end{array}$ \\
\hline Vista & $\begin{array}{l}\text { "La creciente esta que vemos es la } \\
\text { más grande de todas las que han } \\
\text { bajado el río en muchos años". }\end{array}$ & $\begin{array}{l}\text { Magnitud de la creciente: grande, } \\
\text { se percibe por la vista. }\end{array}$ \\
\hline Vista & $\begin{array}{l}\text { "Agua revuelta". } \\
\text { "Aquel amontonadero de agua que } \\
\text { cada vez se hace más espesa y } \\
\text { oscura". } \\
\text { "Aquella agua negra". }\end{array}$ & $\begin{array}{l}\text { Revuelta, espesa, oscura, negra } \\
\text { son cualidades que se perciben } \\
\text { por el sentido de la vista. }\end{array}$ \\
\hline Tacto & $\begin{array}{l}\text { "El agua pesada le golpeaba las } \\
\text { costillas". }\end{array}$ & El agua puede dar golpes. \\
\hline Tacto & $\begin{array}{l}\text { "El agua fría que caía del cielo } \\
\text { quemaba aquella cebada". }\end{array}$ & Expresa la temperatura del agua. \\
\hline Tacto & $\begin{array}{l}\text { "Aquella agua negra y dura como } \\
\text { tierra corrediza". }\end{array}$ & $\begin{array}{l}\text { La dureza y la espesura, aunque } \\
\text { se pueden percibir por la vista, } \\
\text { solo se constatan por el sentido } \\
\text { del tacto. }\end{array}$ \\
\hline
\end{tabular}




\begin{tabular}{|l|l|}
\hline "Aquel amontonadero de agua que \\
cada vez se hace más espesa y \\
oscura".
\end{tabular} \mid

Fuente: Elaboración propia

En el texto, el agua del río tiene olor a podrido. Fontanille (2016a) afirma que el olor significa y que el olor a podrido, en específico, procede de un estado heterogéneo en el que hay desunión de la materia orgánica, que indica el paso de la unidad a la pluralidad y de la vida a la muerte. Efectivamente, el río del cuento lleva animales muertos como la vaca, así como los árboles que ha arrancado y tierra. La unidad que era el río ha dado paso a una mezcla heterogénea, donde lo vivo que ha arrastrado el río ahora muere en él y se descompone. El proceso de putrefacción se pone de manifiesto en el olor que desprende.

\section{Las acciones del agua}

Al ser perceptible por todos los sentidos, incluso por el del intelecto, pues el narrador emite juicios, califica e hipotetiza con respecto al agua, este elemento se va perfilando como un personaje más, pues además de esto realiza, como se verá más adelante, múltiples acciones (las principales del cuento) e interactúa con los personajes. Juan Rulfo convierte al agua en uno de los personajes principales del cuento. La mayor parte del cuento se centra en las acciones del agua y sus consecuencias. Al respecto de la relación escritor-obra, en relación con fenómenos de la naturaleza y en particular con el agua, Lanzuela (2009) comenta:

Así pues, el poeta contempla el mundo transformado en ser animado y he aquí que este le habla. De hecho, este macroantropos, que es el cosmos, no es mudo, sino todo lo contrario, posee un cuerpo, una mirada, un soplo, una voz humana. Es Gaston Bachelard (1978) quien lo recuerda en varias ocasiones: “Así, el agua va a aparecérsenos como un ser total: tiene un cuerpo, un alma, una voz. Quizá más que cualquier otro elemento, el agua es una realidad poética completa" (p. 30).

En el cuento, el agua parece tener cuerpo por las acciones que realiza y la forma en que se mueve. Además, tiene impacto en el mundo social de los personajes, como más adelante se verá. La acción del agua que viene del cielo es únicamente llover, manifestarse en un aguacero, en olas de agua y nublazones. El impacto que tienen sus acciones se presenta en la crecida del río. El agua que viene del cielo se presenta como la causa de lo que sucede 


\section{Revista Iberoamericana \\ de las Ciencias Sociales y Humanísticas}

ISSN: $2395-7972$

en el cuento. Por otro lado, el efecto es el río crecido. Al mismo tiempo, el río se convierte en la causa de la inundación y las pérdidas materiales, e incluso se asocia con daños morales. Las acciones del río se sintetizan en la tabla 7.

Tabla 7. Las acciones del agua, sus implicaciones y consecuencias

\begin{tabular}{|c|c|}
\hline Acción & Implicaciones y consecuencias \\
\hline Crece & $\begin{array}{l}\text { Al hacerlo, inunda el pueblo, generando pérdidas } \\
\text { materiales. }\end{array}$ \\
\hline Traer estruendo & $\begin{array}{l}\text { Indicador del crecimiento y de la intensidad de la corriente } \\
\text { y la inundación. }\end{array}$ \\
\hline Perder las orillas & Indicador de la inundación. \\
\hline Subir por la calle & Indicador de la inundación \\
\hline Meterse en una casa & Indicador de inundación y de pérdidas materiales. \\
\hline Entrar y salir del corral & Indicador de inundación y de pérdida de animales. \\
\hline Causar perjuicios & Daño económico y estructural. \\
\hline $\begin{array}{l}\text { Arrastrar cosas, vegetales y } \\
\text { animales }\end{array}$ & Indicador de pérdidas materiales. \\
\hline Matar & $\begin{array}{l}\text { Mata a la vaca de Tacha, la arrastra, la voltea y se la lleva. } \\
\text { Esta acción del río es la que genera un daño social y moral } \\
\text { a Tacha. La condena a la perdición. }\end{array}$ \\
\hline
\end{tabular}

Fuente: Elaboración propia

La crecida del río es el centro de las acciones del cuento. En el pueblo no se había visto una crecida así en muchos años, pero no se afirma que nunca. Las poblaciones cerca de ríos suelen sufrir este tipo de desastres. Al respecto, Vergara, Ellis, Cruz, Alarcón y Galván (2011) comentan lo puesto a continuación:

Sin embargo, aunque las inundaciones han estado presentes en la historia de las civilizaciones desde sus inicios, son uno de los eventos naturales que cada vez más afectan de manera contundente a las poblaciones y que provocan incomunicación, pérdidas humanas, materiales y económicas. (p. 46)

Es claro que, aunque las inundaciones estén presentes en el pasado de una población, son materia de preocupación y desastre para la población que en el momento las vive, ese parece ser el objetivo de cuento: dejar en claro la magnitud de los daños materiales y sociales 
Revista Iberoamericana

de las Ciencias Sociales y

Humanísticas

ISSN: $2395-7972$

que pueden acarrear, la forma diferente en que el río se puede comportar y sus implicaciones sociales.

Fontanille (2016b) indica que un objeto se puede convertir en un cuerpo y hasta en un actor si posee sus propiedades:

1) Una estructura material dinámica, capaz, bajo la presión de las energías autoorganizadas.

2) Una estructura figurativa que incluye, de un lado, una envolturasuperficie de inscripción (la forma-envoltura), y del otro lado, un movimiento (la fuerza o cuerpo máquina).

3) Un rol actancial.

4) Una identidad modal y temático-figurativa, que le abre campo al accidente, al azar y a la contingencia, y que define al cuerpo-actor (p. 328).

El río en el cuento cumple con estas características: el agua es un conjunto de partículas de agua, bajo la presión de las fuerzas naturales que la autoorganizan como río, que es su envoltura, con un movimiento continuo que se manifiesta en la corriente. Su concepción como actante se define por sus acciones (crecer, traer, subir por la calle, meterse en una casa, entrar y salir del corral, causar perjuicios, arrastrar y matar), se mueve como un ser vivo, con un cuerpo. Está sujeto a la lluvia que lo hizo crecer, causa daños materiales y morales, como se verá en el siguiente apartado de este trabajo, por lo que recibe propiedades actanciales complejas como verse ligado a aspectos morales.

\section{La correlación entre determinismo natural y determinismo social}

Con base en lo visto anteriormente, pudiera parecer que la naturaleza periódicamente acarrea desastres como la inundación del pueblo en el cuento y que esa inundación se puede medir en términos de pérdidas materiales o físicas. Nadie pierde la vida en el cuento, pero el agua tiene un impacto social-moral en el texto. El río ha matado a la vaca de la Tacha, la Serpentina, y posiblemente a su becerro aunque a nadie consta que se lo ha llevado el río. El narrador, el hermano de Tacha, afirma con respecto al becerro: “Ojalá que no se le haya ocurrido pasar por el río detrás de su madre. Porque si así fue, mi hermana Tacha está tantito así de retirado de hacerse piruja" (Rulfo, 1983, p. 32). Además, la vaca era una posesión importante para Tacha, pues aseguraba su bienestar futuro, no solo económico, pues el 


\section{Revista Iberoamericana de las Ciencias Sociales y Humanísticas}

narrador precisa: "Con la vaca era distinto, pues no hubiera faltado quien se hiciera el ánimo de casarse con ella, solo por llevarse también aquella vaca tan bonita" (Rulfo, 1983, p. 32).

Al parecer no hay virtud que valga para que Tacha encuentre marido; antes de la pérdida, alguno podría "hacerse el ánimo" de casarse con ella solo para llevarse a la vaca. Ante esta situación, el único motivo de esperanza es el becerro: "La única esperanza que nos queda es que el becerro esté todavía vivo" (Rulfo, 1983, p. 32). El becerro es el otro bien material que podría salvar a Tacha de la perdición. Rulfo deja claro el valor social de las posesiones materiales para una muchacha pobre, pues le abren la posibilidad al matrimonio. Por tanto, el desastre natural, la inundación, está condenando a Tacha a la perdición.

También se alude al determinismo social. El narrador nos dice con respecto a sus otras hermanas: "Según mi papá, ellas se habían echado a perder porque éramos muy pobres en mi casa y ellas eran muy retobadas" (Rulfo, 1983, p. 31). Pero este determinismo social se asocia con el agua del río: "Iban cada rato por agua al río y a veces, cuando uno menos se lo esperaba, allí estaban en el corral, revolcándose en el suelo, todas encueradas y cada una con un hombre trepado encima" (Rulfo, 1983, p. 32). Ir por el agua del río era un pretexto para las hermanas para yacer con hombres en el corral. Esta correlación entre ser pobres e ir por agua al río no parece ser algo que Rulfo haya puesto al azar en un cuento donde las acciones centrales son realizadas por el río. La perdición de las hermanas de Tacha también guarda relación con el río y su destino social: "Ellas se fueron para Ayutla, o no sé para dónde; pero andan de pirujas" (Rulfo, 1983, p. 32). El padre de las hermanas de Tacha afirma que la situación "ya no tiene remedio" (Rulfo, 1983. p. 33). Eso confirma el determinismo social.

Otro elemento que reafirma el determinismo natural, aparte del agua, es cuando se compara a Tacha con el palo de ocote: "La peligrosa es la que queda aquí, la Tacha, que va como palo de ocote crece y crece y que ya tiene unos comienzos de senos que prometen ser como los de sus hermanas: puntiagudos y altos y medio alborotados para llamar la atención." (Rulfo, 1983, p. 33). El desarrollo natural del cuerpo de Tacha como crecer y el desarrollo de los senos son suficientes para considerarla peligrosa y sus senos, no ella, llamarán la atención de los hombres. Aquí es donde entra el determinismo de la naturaleza también.

Además de lo anterior, el río sucio, ese que ha ocasionado pérdidas y desgracias, parece haber entrado dentro de Tacha: "Por su cara corren chorretes de agua sucia como si el río se hubiera metido dentro de ella" (Rulfo, 1983, p. 33). Aunado a esto, el contacto de Tacha con el agua del río está ligado a su perdición: 


\section{Revista Iberoamericana de las Ciencias Sociales y Humanísticas}

El sabor a podrido que viene de allá salpica la cara mojada de Tacha y los dos pechitos de ella se mueven de arriba abajo sin parar, como si de repente comenzarán a hincharse para empezar a trabajar con su perdición (Rulfo, 1983, p. 34).

El contacto con el olor a podrido del agua que salpica la cara de Tacha y el movimiento del pecho que hace su cuerpo al llorar se perciben como una señal de perdición. Y no por la voluntad de Tacha, como ser pensante con una voluntad, sino como un acto propio de sus pechos. La sola acción de hincharse de los pechos es una señal de perdición y, en realidad, ni siquiera se han hinchado, se trata sólo del movimiento natural de los pectorales cuando se solloza o se llora, pero es la percepción del narrador.

En el cuento existen varias metáforas conceptuales mediante las que se puede entender el impacto del agua en la percepción de la realidad. Está claro que hay una visión negativa en torno al agua, puesto que esta, en sus variadas formas, ha hecho estragos en el pueblo. Las metáforas aparecen sobre todo en la parte final del cuento y son elementales para entender cómo el agua impacta también en la percepción de las tres hermanas del narrador. La siguiente cita: “-Sí — dice—, le llenará los ojos a cualquiera dondequiera que la vean” (Rulfo, 1983, p. 33) expresa ya la resignación del papá sobre el destino que tendrá Tacha, al igual que sus hermanas mayores. Pero también esta frase expresa la conceptualización del cuerpo de Tacha como un líquido que "llenará" los ojos de cualquiera. Según Lakoff y Johnson (2015), esto tiene sentido por lo siguiente: "Se trata de una metáfora natural, que resulta del hecho de que cuando uno mira hacia un territorio (tierra, suelo, etc.), su campo visual define una frontera, es decir, la parte que uno puede ver" (Lakoff y Johnson, 2015, p. 68). Y no solo es el hecho de que el campo visual se perciba como recipiente, sino que esta forma de entender el campo visual convierte a Tacha en una sustancia que se ha de introducir en unos ojos, lo cual va en relación con las siguientes citas, en las que parece que Tacha sufre de manera directa las acciones negativas que realiza el río. La siguiente cita permite ver el contacto entre Tacha y el río: "Por su cara corren chorretes de agua sucia como si el río se hubiera metido dentro de ella" (Rulfo, 1983, p. 33), lo cual expresa ya una fusión entre el agua del río y el cuerpo de Tacha (expresado anteriormente como líquido y ahora también como recipiente). Las siguientes dos citas ayudarán a percibir la influencia del río sobre Tacha: "De su boca sale un ruido semejante al que se arrastra por las orillas del río" (Rulfo, 1983, p. 34). El narrador percibe ya que su hermana Tacha emite un ruido semejante al que 


\section{Revista Iberoamericana \\ de las Ciencias Sociales y Humanísticas}

ISSN: $2395-7972$

produce el río, lo que va en relación con la cita anterior, en la que parece que Tacha ha adoptado más cualidades del río. El hecho de que el narrador comience a hacer comparaciones entre Tacha y el río da la pauta para pensar en la magnitud con la que el río ha hecho estragos también en ella. La siguiente cita lo termina por confirmar:

El sabor a podrido que viene de allá salpica la cara mojada de Tacha y los dos pechitos de ella se mueven de arriba abajo, sin parar, como si de repente comenzaran a hincharse para empezar a trabajar por su perdición (Rulfo, 1983, p. 34).

Esta frase está compuesta por dos oraciones que se unen por una conjunción y parece haber una relación de causa-efecto entre la oración uno y la oración dos. Esta frase resume de manera concreta que el contacto con el agua ha tenido como consecuencia la hinchazón de sus "pechitos". Para entender esta frase, debe entenderse que el "sabor a podrido" se utiliza para referirse al agua del río, la cual "salpica” la cara de Tacha. Es solo una expresión más que confirma el contacto que tienen el río y Tacha, puesto que el narrador está exento de esto. Sin embargo, es tras este último contacto con el agua que sucede el movimiento y crecimiento de los pechos de Tacha, que posteriormente el narrador relaciona con su futuro de perdición. De igual manera puede entenderse la forma de ser de las otras dos hermanas por el contacto que tuvieron con el río, pues es este elemento el que aparece en el cuento como el productor de desgracias.

Todo esto se puede entender considerando lo que se ha dicho sobre el agua. Las cualidades físicas del agua sucia y revolcada del río parecen ser portadoras de cualidades de tipo moral, que parecen influir sobremanera en las mujeres y específicamente en las hermanas del narrador. Por último, quedaría agregar la siguiente cita "Según mi papá, ellas se habían echado a perder porque éramos muy pobres" (Rulfo, 1983, p. 34). En este caso vale la pena detenerse en la expresión "echar a perder", como si se tratara de una fruta o carne, una similitud entre las hermanas mayores y el agua del río que inunda, la cual también se ha echado a perder, pues huele a podrido.

El agua suele asociarse a lo masculino y lo femenino. Al respecto, Soler (1999) afirma:

El agua posee valores masculinos, como el de fertilizar, recordemos la obra de García Lorca "Yerma", la mujer recibe aquí el mismo adjetivo que se da a la tierra estéril. Pero también posee valores femeninos, el agua que está dentro 
de la tierra y que hace fertilizar la vida. El agua de la lluvia sería así masculina y la de manantial o pozo, femenina (p. 684-685).

En "Es que somos muy pobres", el desencadenante de la inundación del río es el agua de la lluvia, que, siguiendo esta cita, sería masculina (vertical y con fuerte intensidad). El río que se desborda, inunda y destruye viene nutrido de esta agua de lluvia masculina. Pero es el contacto con las hermanas del narrador lo que reafirma el carácter masculino del agua del río. Pues simbólicamente las condena a la perdición como lo hubiera hecho un hombre, como de si un hombre se tratara cuando Tacha y sus hermanas tienen contacto con su agua.

\section{Discusión}

Los hallazgos realizados con el análisis del cuento implican que 1) el agua es un actor, las acciones del agua son el foco de lo dicho por el narrador. Esto implica, a su vez, que un elemento natural y no animado como el agua se concibe con acciones de un sujeto que se desplaza por un pueblo. Es poco frecuente encontrar obras literarias donde el centro de las acciones sea un elemento natural. 2) El hecho de que las cualidades y varias de las acciones del agua sean negativas y violentas refleja que el agua se percibe con cualidades no presentes en el concepto tradicional y cultural del agua. Es como si Juan Rulfo estuviera presentando de manera intencional la parte nociva del agua. El hecho de que no se asocie a la vida sino a la muerte está dado por cualidades asociadas a lo oscuro, denso y putrefacto, culturalmente asociadas al lodo y a la muerte. 3) Las variadas formas de nominar el agua representan la multiplicidad que puede tomar este elemento líquido en la realidad natural y social del ser humano, y esta multiplicidad está asociada a la orientación del agua en los estados en que se encuentra y la forma en que se desplaza. 4) La relación entre el determinismo natural y social indica que la visión que se plantea en el cuento es que un elemento de la naturaleza puede funcionar como factor determinante del destino social de una mujer.

Los hallazgos realizados corroboran la hipótesis de que el agua se percibe con cualidades negativas, tanto en el plano natural como en el social, y esto se manifiesta de principio a fin en el texto analizado.

La percepción del agua es negativa, se percibe como elemento nocivo y con cualidades que se contraponen a los atributos del concepto cultural del agua. El análisis realizado puede inspirar el estudio de los fenómenos naturales y elementos de la naturaleza en la obra de Juan Rulfo. El presente estudio se limita a tratar la percepción del agua por 
Revista Iberoamericana

de las Ciencias Sociales y

Humanísticas

ISSN: $2395-7972$

parte del narrador en primera persona. Se deja abierta la puerta para el estudio del agua como actante y como actor en el cuento "Es que somos muy pobres" para futuras investigaciones.

Con respecto a la obra de Juan Rulfo, este cuento no es el único en el que se presenta un enfrentamiento del hombre con factores climáticos o elementos de la naturaleza, otros cuentos refieren a la tierra árida o a un terremoto, por ejemplo.

Estudios anteriores a este han trabajado, sobre este mismo cuento, temas como las metáforas del río y la leche por Salazar (1996) y la ideología en "Es que somos muy pobres" por Campbell (1991). Con respecto al ambiente y fenómenos meteorológicos, geológicos y aspectos geográficos, Bell (2015) presenta una ecocrítica del Llano en llamas. Como se puede observar, estudios antecedentes ya han abordado el río en el aspecto metafórico y los fenómenos meteorológicos y geológicos, pero el presente artículo se enfoca en el agua y el fenómeno de percepción sensorial respecto a ella.

\section{Conclusiones}

En el cuento "Es que somos muy pobres", el agua se presenta en su versión destructiva. La percepción del agua en el texto es a través del intelecto y sentidos del narrador, quien la nomina de diversas formas y la califica con atributos negativos. El agua del río ha sufrido una transformación tal que rompe con las cualidades prototípicas al punto de poder ser percibida por todos los sentidos (gusto, tacto, olfato, vista y oído). Se manifiesta con un cuerpo como un personaje y realiza acciones perjudiciales e invasivas y aparece ligada a lo moral, pues se asocia a la perdición de las hermanas del narrador. Se presenta como elemento fundamental del determinismo natural que aparece en el texto e interrelacionado al determinismo social. El río crecido y el narrador son los personajes principales del cuento. El río tiene un rol activo y el narrador un rol pasivo. El río crecido se manifiesta y el narrador lo percibe, lo describe y emite juicios. El cuento enviste al agua con cualidades actanciales como símbolo de destrucción y con características opuestas al concepto cultural del agua. 


\section{Futuras líneas de investigación}

A partir del análisis realizado en el presente artículo, se puede observar que surgen puntos de interés y abordaje para futuras investigaciones como lo son: 1) El análisis del texto literario a partir de las neurociencias cognitivas, para profundizar en la forma en que se percibe y conceptualiza en un texto literario. 2) Otro campo de interés para la investigación es la lingüística cognitiva, desde la cual se pueden abordar las diversas formas de llamar al agua, así como su aspecto, desde la teoría de la metáfora conceptual: función, estructura y analogía. 3) En el área de lo social, el trabajo ofrece áreas de interés para las ciencias sociales, desde la sociología de la literatura se puede trabajar de manera específica y profunda el determinismo social presente en el cuento. 4) El texto se puede abordar interdisciplinariamente por parte de ciencias naturales como la meteorología y la geología, como ya se ha mencionado en un apartado anterior, pero también está la hidrología y los estudios del paisaje por parte de la geografía para estudiar el agua y los escenarios naturales y rurales que se presentan en el cuento. 5) Finalmente, está el abordaje desde la antropología cultural y la antropología lingüística que tienen el campo abierto para investigar sobre las expresiones utilizadas en el texto para denominar el agua, así como los factores culturales asociados al agua presentes en el cuento de Juan Rulfo. 


\section{Referencias}

Bachelard, G. (1978). El agua y los sueños. Ensayo sobre la imaginación de la materia. México: Fondo de Cultura Económica.

Bell, L. (2015). Viscous Porosity: Interactions between Human and Environment in Juan Rulfo's El llano en llamas. Journal of Iberian and Latin American Research, 21(3), 389-404.

Campbell, Y. (1991). La ideología en "Es que somos muy pobres” de Juan Rulfo. La Palabra y el Hombre, (78), 280-286. Recuperado de https://cdigital.uv.mx/handle/123456789/42636.

Chevalier, J. y Gheerbrant, A. (1995). Diccionario de los símbolos. España: Editorial Herder. Fernández, C. A. (2012). El agua: un recurso esencial. Química Viva, 11(3), 147-170. Recuperado de http://www.quimicaviva.qb.fcen.uba.ar/.

Fontanille, J. (2016a). Semiótica del discurso. Lima, Perú: Universidad de Lima.

Fontanille, J. (2016b). Soma y sema. Figuras semióticas del cuerpo. Lima, Perú: Universidad de Lima.

Lakoff, G. y Johnson, M. (2015). Metáforas de la vida cotidiana (10. a ed.). España: Ediciones Cátedra.

Lanzuela, J. H. (2009). La imaginación simbólica del agua: el diálogo permanente entre el hombre y el cosmos. Studium: Revista de Humanidades, (15), 199-223. Recuperado de http://studium.unizar.es/index.html.

Lupón, M., Torrents, A. y Quevedo, L. (2012). Procesos cognitivos básicos. España: Universidad Politécnica de Cataluña.

Rivera, J., Arellano, R. y Molero, V. (2000). Conducta del consumidor. Estrategias y tácticas aplicadas al marketing. España: ESIC Editorial.

Rodríguez, R. y Silva, T. (2003). Conservación de la calidad del agua subterránea: Reto de fin de milenio. En Ávila, P. (ed.), Agua, medio ambiente y desarrollo en el siglo XXI: México desde una perspectiva global y regional (pp. 165-174). México: El Colegio de Michoacán, Secretaría de Urbanismo y Medio Ambiente, Instituto Mexicano de Tecnología del Agua.

Rulfo, J. (1983). El llano en llamas. México: Fondo de Cultura Económica. 
Revista lberoamericana

de las Ciencias Sociales y Humanísticas

ISSN: 2395 - 7972

Salazar, S. (1996). Las metáforas del río y de la leche en "Es que somos muy pobres" de Juan Rulfo. La Palabra y el Hombre, (100), 59-66. Recuperado de https://cdigital.uv.mx/handle/123456789/42636.

Smith, E. y Kosslyn, S. (2008). Procesos cognitivos. Modelos y bases neurales. Madrid, España: Pearson Educación.

Soler, D. (1999) ¿Más claro que el agua? Estudio monográfico en torno al agua. Para cursos avanzados de ELE. En Franco, M., Soler, C., de Cos, J., Rivas, M. y Ruiz, F. (eds.), Nuevas perspectivas en la enseñanza del español como lengua extranjera. Tomo II (pp. 685-693). España: Servicio de Publicaciones de la Universidad de Cádiz.

Vargas, L. (1994). Sobre el concepto de percepción. Alteridades, 4(8), 47-53. Recuperado de https://alteridades.izt.uam.mx/index.php/Alte/index.

Vergara, M. del C., Ellis, E., Cruz, J. A., Alarcón, L. del C. y Galván, U. (2011). La conceptualización de las inundaciones y la percepción del riesgo ambiental. Política y Cultura, (36), 45-69. $\quad$ Recuperado de https://polcul.xoc.uam.mx/index.php/polcul/index.

Zilberberg, C. (2016). De las formas de vida a los valores. Lima, Perú: Universidad de Lima. 